\title{
APLIKASI TEKNOLOGI ELEKTRONIK LOG BOOK PENANGKAPAN IKAN UNTUK MENDUKUNG PENGELOLAAN PERIKANAN
}

\author{
THE APPLICATION OF FISHING ELECTRONIC LOG BOOK TO SUPPORT FISHERIES \\ MANAGEMENT
}

\author{
Hadhi Nugroho'), Agus Sufyan ${ }^{1)}$ dan Ngurah N. Wiadnyana ${ }^{2)}$ \\ ${ }^{1)}$ Pusat Penelitian dan Pengembangan Sumberdaya Laut dan Pesisir \\ Jl. Pasir Putih II, Ancol Timur, Jakarta Utara \\ Email: hadhinugroho@gmail.com \\ ${ }^{2)}$ Pusat Penelitian dan Pengembangan Perikanan \\ Jl. Pasir Putih II, Ancol Timur, Jakarta Utara
}

Diterima tanggal : 24 Oktober 2016, diterima setelah perbaikan : 30 Januari 2017, disetujui tanggal 16 Februari 2017

\begin{abstract}
ABSTRAK
Kebijakan pengelolaan perikanan yang berkelanjutan memerlukan dukungan data penangkapan ikan yang akurat. Salah satu cara untuk memperoleh data hasil tangkapan ikan adalah penggunaan log book penangkapan ikan. Kenyataan di lapangan menunjukkan penggunaan log book secara manual banyak mengalami kendala. Berdasarkan data tahun 2013, dari 189.800 kapal dengan kewajiban melaporkan log book, hanya 6.507 kapal $(3,43 \%)$ yang sudah melaporkan $\log$ book. Untuk mengatasi kendala dalam pengisian log book penangkapan ikan secara manual, telah dikembangkan teknologi elektronik log book selama kurun waktu 2011-2014. Untuk penerapan $e$-log book di Indonesia, diperlukan suatu kajian yang menguraikan aspek teknis dari teknologi $e$-log book, perbandingan penerapan e-log book di sejumlah negara, serta strategi penerapannya di bidang perikanan di Indonesia. Penerapan e-log book di Indonesia dapat dilakukan dengan melihat perbandingan penerapan $e$-log book penangkapan ikan di negara lain, serta melihat kondisi di Indonesia. Berdasarkan analisis kesenjangan penerapan teknologi e-log book di Indonesia, maka secara teknologi, e-log book yang dikembangkan sudah siap untuk digunakan dalam bidang pengelolaan sumber daya ikan ditinjau dari aspek perangkat keras, perangkat lunak, komunikasi data (satelit dan GSM/GPRS), dan sistem integrator. Sedangkan dari sisi landasan peraturan, perlu dibuat suatu peraturan hukum sebagai landasan bagi penerapan e-log book di Indonesia. Rekomendasi strategi penerapan e-log book adalah sebagai berikut: (i) penerapan penggunaan $e$-log book dilakukan di pelabuhan perikanan dengan tingkat kepatuhan pelaksanaannya yang tinggi dan di kapal-kapal penangkap ikan yang sudah menggunakan transmitter VMS; (ii) sosialisasi dan pelatihan penggunaan e-log book pada nelayan secara intensif; (iii) pemberian sanksi yang tegas terhadap pelanggaran pelaksanaan $e$-log book; dan (iv) mengembangkan kerja sama dengan pihak ketiga seperti perusahan di bidang teknologi komunikasi.
\end{abstract}

Kata Kunci: elektronik log book, Penangkapan Ikan, Pengelolaan Perikanan

\begin{abstract}
Fisheries management policy needs the support of accurate fishing data. One way to acquire the fish catch data is the use of fishing log book. The fact shows that the use of the log book manually on the ground faced to many obstacles. Based on data of 2012, from 189,800 fishing vessels with an obligation to report the log book, only 6,507 fishing vessels $(3.43 \%)$ have reported the log book. To overcome the obstacles in filling of fishing log book manually, it was developed a technology of electronic log book (e-log book) in 2011-2014. To implement e-log book in Indonesia, it was needed a study outlining the technical aspects of the e-log book, a comparison of e-log book in a number of countries, as well as implementation strategies in the field of fisheries in Indonesia. Implementation of e-log book in Indonesia can be done by studying implementation of fishing e-logbook in other countries, as well as comparing with the conditions in Indonesia. Based on the gap analysis of e-log book technology application in Indonesia, e-log book is technologically ready to be applied in fishery domain from point of view of hardware, software, data communication (satellite and GSM/GPRS), and integrator system aspects. Meanwhile, a regulation should be prepared as a legal base for e-logbook application in Indonesia. Recommendations on the strategy to implement the fishing e-log book are as follows: (i) e-log
\end{abstract}

Aplikasi Teknologi Elektronik Log Book Penangkapan Ikan Untuk Mendukung Pengelolaan Perikanan - Hadhi 
book can be implemented in the fishing port with high level of its compliance and on board fishing vessels using VMS transmitter; (ii) intensive socialization and training to the fishermen in using e-log book, (iii) strict sanctions against violations of the of e-log book implementation; (iv) developing the cooperation with third parties, especially with companies dealing with communication technology.

Key Words: Electronic log book, Fishing, Fisheries Management

\section{PENDAHULUAN}

Indonesia merupakan negara kepulauan dan bahari yang memiliki potensi sumber daya ikan. Potensi perikanan ini dapat diandalkan untuk memenuhi konsumsi domestik dan penghasil devisa negara. Untuk itu, perlu dilakukan pengelolaan perikanan secara tepat agar sumber daya ikan dapat dimanfaatkan secara berkesinambungan (KKP dan JICA, 2009). Untuk mendukung kebijakan pengelolaan perikanan yang berkelanjutan serta dapat menjamin kelestarian sumber daya ikan, diperlukan data perikanan yang akurat dari hasil kegiatan penangkapan ikan. Data perikanan dapat dikumpulkan baik secara rutin (statistik) maupun tidak rutin (riset) (Noviyanti, 2011).

Salah satu cara untuk memperoleh data penangkapan ikan yang akurat adalah dengan menggunakan log book penangkapan ikan, yaitu laporan harian tertulis nakhoda kapal mengenai kegiatan penangkapan ikan (Republik Indonesia, 2010). Log book penangkapan ikan merupakan surat pernyataan nakhoda (landing declaration) dari nakhoda atau mengenai ikan yang ditangkap dan didaratkan di pelabuhan perikanan (Direktorat Sumber Daya Ikan, 2014). Penerapan log book penangkapan ikan di Indonesia saat ini diatur dalam Peraturan Menteri Kelautan dan Perikanan No. 48/PERMEN-KP/2014 tentang Log book Penangkapan Ikan. Peraturan ini menggantikan Peraturan Menteri Kelautan dan Perikanan No. PER.18/MEN/2010. Jenis informasi yang terdapat pada log book meliputi data kapal perikanan, alat penangkapan ikan, operasi penangkapan ikan dan ikan hasil tangkapan.

Kenyataan di lapangan, penggunaan log book secara manual banyak mengalami kendala. Kendala-kendala tersebut antara lain adalah banyaknya data yang harus diisi dan tulisan tidak mudah terbaca. Kasus lainnya, kertas yang mudah basah dan sobek serta masalah kerahasiaan lokasi penangkapan menyebabkan log book tidak diiisikan secara benar. Selain itu, penerapan log book masih belum memberikan manfaat langsung kepada nelayan, sehingga mereka tidak merasa memiliki kewajiban untuk melakukan pengisian hasil penangkapannnya pada borang log book yang sudah ditetapkan (Marzuki, 2010).

Berdasarkan data pada 2013, dari 189.800 kapal secara keseluruhan yang wajib melaporkan log book, hanya 6.507 kapal $(3,43 \%)$ yang sudah melaporkan log book. Secara lebih rinci jumlah kapal yang wajib melaporkan log book di UPT pusat dan daerah masing-masing sebanyak 4.391 dan 185.409 kapal. Namun jumlah kapal yang melakukan kewajiban melaporkan log book dari UPT pusat dan UPT daerah masing-masing sebanyak 1.317 dan 5190 kapal (Direktorat Jenderal Perikanan Tangkap, 2014). Rendahnya tingkat pelaksanaan log book ini tampaknya disebabkan belum adanya sosialisasi yang intensif dan pemberian sanksi yang tegas dalam pelaksanaan peraturan menteri tersebut.

Untuk mengatasi kendala dalam pengisian log book penangkapan ikan secara manual, telah dikembangkan log book penangkapan ikan berbasis elektronik atau dikenal dengan elektronik log book. Dengan penggunaan elektronik log book, akan diperoleh data dan informasi perikanan yang lebih akurat terkait dengan kegiatan penangkapan ikan, sehingga dapat mendukung kebijakan pengelolaan sumber daya ikan yang optimal dan berkelanjutan serta terjaminnya kelestarian sumber daya ikan. Tujuan penelitian ini adalah melakukan kajian penerapan $e$-log book di Indonesia yang menguraikan aspek teknis dari teknologi e-log book, perbandingan penerapan elog book di sejumlah negara, serta strategi 
penerapannya untuk pengelolaan sumber daya ikan yang berkelanjutan.

\section{BAHAN DAN METODE}

Metode penelitian yang digunakan adalah dengan mengkaji secara teknis e-log book yang sudah dikembangkan oleh P3TKP tahun 2011-2014 dan studi literatur tentang teknologi dan penerapan $e$ log book di beberapa negara. Dengan melihat aspek teknis pada teknologi e-log book, studi literatur tentang penerapan $e$-log book di sejumlah negara, serta melihat kondisi saat ini di Indonesia, kemudian dibuat analisis kesenjangan penerapan teknologi e-log book di Indonesia. Analisis kesenjangan adalah analisis yang dibuat dengan membandingkan kondisi yang diharapkan / ideal dengan kondisi yang ada saat ini.

\section{HASIL DAN PEMBAHASAN}

\section{Pengembangan E-Log Book}

Secara umum, prinsip kerja elektronik log book dapat dijelaskan pada Gambar 1. Di atas kapal, nelayan atau kapten kapal mengisi data tangkapan ikan ke dalam elektronik log book. Selain data tangkapan ikan, alat ini juga dilengkapi dengan fitur rekam jejak kapal. Data rekam jejak kapal ini dapat diatur otomatis setiap jam, sehingga dapat diketahui pergerakan kapal dari berangkat hingga berlabuh kembali di pelabuhan. Semua data tersebut akan dikirim ke web server melalui jaringan GPRS (General Packet Radio Service). Jika tidak terdapat sinyal GPRS, maka data tersebut akan disimpan di perekam data (data logger). Setelah menerima kembali sinyal GPRS, maka semua data yang tersimpan di perekam data akan terkirim secara otomatis ke web server. Web server ini menampilkan semua data yang dikirim dari alat elektronik log book (Marzuki dan Nugroho, 2013).

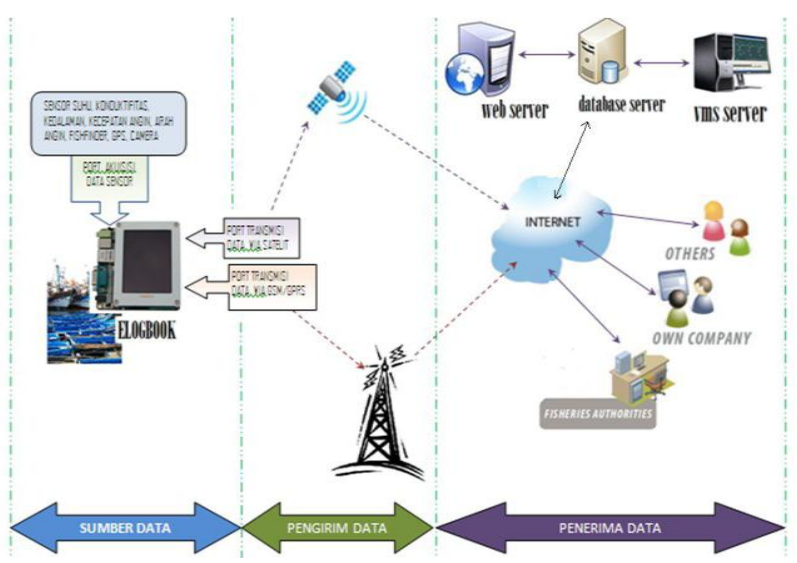

Gambar 1. Prinsip kerja e-log book penangkapan ikan

Figure 1. Work methods of fishery electronic log book.

(Sumber: Marzuki, 2011).

Tahapan pengembangan teknologi e-log book berlangsung selama periode 2011-2014. Pada 2011, dilakukan rancang bangun e-log book berbasis keypad dan LCD. Kemudian pada 2012, dikembangkan teknologi e-log book berbasis ARM dan layar sentuh. Pada 2012 juga dilakukan integrasi e-log book dengan sistem pemantauan kapal perikanan (VMS). Pada 2013, dikembangkan teknologi e-log book berbasis layar sentuh berdasarkan pada teknologi yang diperoleh pada 2012. Pengembangan tersebut meliputi perubahan ukuran layar sentuh menjadi lebih besar, penambahan pengisi baterai portabel, perubahan sistem penyimpanan data, dan penyesuaian fitur/format isian data dengan format data $\log$ book pada Peraturan Menteri Kelautan dan Perikanan No. PER.18/MEN/2010 (Nugroho \& Sufyan, 2014). Pada 2014, dikembangkan teknologi e-log book berbasis android. Format data pada aplikasi android menyesuaikan dengan format data log book pada peraturan yang baru, yaitu Peraturan Menteri Kelautan dan Perikanan No. 48/PERMEN-KP/2014. Secara ringkas, perbandingan antara teknologi e-log book yang sudah dihasilkan disajikan dalam Tabel 1.

Tabel 1. Perbandingan teknologi e-log book yang dikembangkan selama periode 2011-2014

Table 1. Comparison of e-log book technology developed during the period of $2011-2014$

Tahun Kemampuan/Fitur E-Log Book 
2011 - Input data menggunakan keypad dan menampilkan data dengan LCD

- Dilengkapi fitur rekam jejak kapal (vessel tracking)

- Dilengkapi dengan sensor suhu

- Ukuran alat: panjang $27 \mathrm{~cm}$, lebar $23 \mathrm{~cm}$, tebal $5 \mathrm{~cm}$

- Input data ke dalam alat harus menggunakan kode angka

2012 - Input data dan menampilkan data menggunakan layar sentuh

- Dilengkapi fitur rekam jejak kapal (vessel tracking)

- Dilengkapi dengan sensor suhu

- Ukuran alat: panjang $18 \mathrm{~cm}$, lebar $11 \mathrm{~cm}$, tebal $4 \mathrm{~cm}$

- Ukuran layar sentuh 3.5"

- Integrasi dengan VMS di Ditjen PSDKP

2013 - Input data dan menampilkan data menggunakan layar sentuh

- Dilengkapi fitur rekam jejak kapal (vessel tracking)

- Dilengkapi dengan sensor suhu

- Ukuran layar sentuh 3.5" dan 7"

- Integrasi dengan VMS di Ditjen PSDKP

- Format data sesuai dengan Permen KP No. PER.18/MEN/2010

- Terdapat fitur yang memberikan informasi yang bermanfaat bagi nelayan, yaitu: informasi cuaca, informasi koordinat PPDPI, informasi harga ikan.

- Terdapat pengisi baterai portabel sebagai baterai cadangan

2014 - Input data dan menampilkan data menggunakan telepon pintar (smartphone) dengan sistem operasi android

- P3TKP hanya membuat aplikasi, di mana aplikasi tersebut daoat diinstal dan digunakan di semua telepon pintar dengan sistem operasi android

- Format data sesuai dengan Permen KP
No. 48/PERMEN-KP/2014

- Penyederhanaan format data isian

\section{Aspek Teknis E-Log Book}

\section{a. Aspek Teknologi}

E-log book penangkapan ikan, yang kemudian cukup disebut e-log book merupakan perangkat keras yang memiliki fungsi input data tangkapan ikan secara elektronik (Marzuki \& Nugroho, 2013). Secara umum, sistem e-log book dibagi menjadi tiga bagian, yaitu sumber data, pengirim data, dan penerima data (Gambar 2).

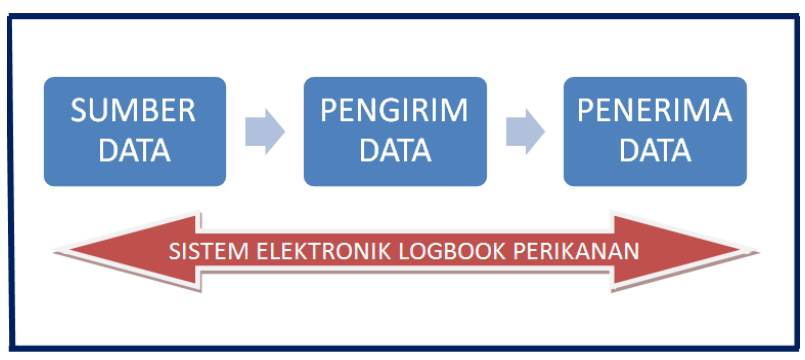

Gambar 2. Skema sistem e-log book.

Figure 2. Schema of e-log book system.

\section{b. Sumber Data}

Bagian sumber data adalah perangkat keras/alat e$\log$ book. Bagian pengirim data memiliki fungsi untuk melakukan transmisi data yang diperoleh dari sumber data ke bagian penerima data. Bagian penerima data berfungsi menerima data yang dikirimkan oleh bagian pengirim data dan mengolah data tersebut sehingga menjadi informasi yang dapat digunakan untuk pengelolaan perikanan berkelanjutan.

Bagian sumber data adalah perangkat keras/alat $e$ log book. Ada dua hal yang harus diperhatikan pada bagian ini, yaitu perangkat keras itu sendiri dan fitur/tampilan/aplikasi pada perangkat tersebut.

Untuk perangkat keras, ada beberapa syarat yang harus dipenuhi, yaitu:

- Bentuknya ringkas, ringan, dan mudah dibawa

JURNAL KELAUTAN NASIONAL, Vol. 10, No. 3, Desember 2015, Hal. 113-124 
- Memiliki layar tampilan yang menarik dan mudah dipahami (user friendly)

- Memiliki baterai untuk penyimpanan daya listrik

- Memiliki sistem operasi

- Dapat membaca posisi koordinat

- Dapat menyimpan dan mengirim data yang diinput ke dalamnya

- Dapat diinstal aplikasi untuk log book penangkapan ikan

- Memiliki nomor identitas khusus, sehingga satu alat hanya dapat digunakan untuk satu kapal

Dari persyaratan tersebut, saat ini di pasaran ada beberapa perangkat yang dapat digunakan sebagai perangkat keras $e$-log book, yaitu:

- Telepon pintar (smartphone), merupakan telepon genggam yang mempunyai kemampuan dengan pengunaan dan fungsi menyerupai komputer. Perangkat ini memiliki memori, prosesor, sistem operasi, serta mendukung GPS dan internet. Telepon pintar memiliki kelebihan karena memiliki ukuran yang kecil dan ringkas. Sistem operasi yang dapat ditemukan di ponsel cerdas antara lain adalah Symbian OS, iOS, RIM BlackBerry, Windows Mobile, WebOS, dan Android.

- Komputer tablet, merupakan suatu komputer portabel lengkap yang seluruhnya berupa layar sentuh datar. Ciri pembeda utamanya adalah penggunaan layar sentuh sebagai peranti masukan dengan menggunakan stilus, pena digital, atau ujung jari.

Untuk perangkat lunak dan tampilan aplikasi pada elektronik log book, ada beberapa hal yang harus diperhatikan, yaitu:

- Perangkat lunak harus dapat dijalankan pada suatu sistem operasi.

- Perangkat lunak dapat di-update tanpa mengganggu sistem yang sudah berjalan.

- Pembuatan menu aplikasi disesuaikan dengan format $\log$ book dalam Peraturan Menteri
Kelautan dan Perikanan No. 48/PERMEN$\mathrm{KP} / 2014$, tetapi disederhanakan untuk memudahkan nelayan dalam melakukan input data ke dalam e-log book.

Agar format data pada $e$-log book lebih sederhana, dapat dilakukan penyederhanaan format log book kertas. Berdasarkan Peraturan Menteri Kelautan dan Perikanan No. 48/PERMEN-KP/2014, data yang terdapat pada log book adalah data kapal penangkap ikan, data alat penangkapan ikan, data operasi penangkapan ikan, serta data ikan hasil tangkapan. Berdasarkan sifatnya, data pada log book tersebut dapat dibagi menjadi dua, yaitu data statis dan data dinamis.

Data kapal penangkap ikan dan data alat penangkapan ikan merupakan data statis. Data ini tidak akan berubah selama operasi penangkapan ikan. Oleh karena itu, data ini tidak perlu diisi oleh nelayan ke dalam e-log book. Data ini dapat disimpan di sisi server, di mana data ini diwakili oleh satu nomor identitas alat. Dengan demikian, nelayan hanya perlu mengisi data dinamis saja, yaitu data operasi penangkapan ikan dan data ikan hasil tangkapan.

Untuk mendukung aktivitas penangkapan ikan bagi nelayan, maka pada elektronik log book dapat ditambah fitur / aplikasi yang dapat memberikan / menyediakan informasi yang bermanfaat bagi nelayan, seperti informasi prakiraan daerah penangkapan ikan, informasi cuaca, informasi harga ikan, dan sebagainya. Hal ini akan memberikan kemudahan dan manfaat bagi nelayan, sehingga diharapkan dapat meningkatkan kepatuhan mereka dalam mengisi elektronik log book.

\section{c. Pengirim Data}

Bagian pengirim data memiliki fungsi untuk melakukan transmisi/komunikasi data yang diperoleh dari sumber data ke bagian penerima data. Ada dua metode komunikasi data utama yang dapat digunakan untuk elektronik log book, yaitu GSM/GPRS dan satelit. Pemilihan metode komunikasi data tersebut dapat dilakukan sesuai dengan kebutuhan. 
Pada penggunaan jaringan GSM/GPRS, alat $e$-log book akan terkoneksi dengan server yang ada di darat secara off line. Artinya jika tidak terdapat sinyal GSM/GPRS, maka data tersebut akan disimpan di perekam data (data logger) pada alat. Data yang tersimpan di perekam data akan terkirim secara otomatis ke server setelah menerima kembali sinyal GSM/GPRS. Kelebihan penggunaan jaringan GSM/GPRS adalah biaya pulsa lebih murah dibandingkan dengan biaya air time jaringan satelit. Sedangkan jika menggunakan jaringan komunikasi satelit, maka e-log book akan terkoneksi dengan server secara online, sehingga data yang dikirimkan merupakan data yang real time. Namun, komunikasi satelit membutuhkan biaya air time yang jauh lebih mahal dibandingkan dengan pulsa GSM/GPRS. Pada e-log book juga dapat digunakan dua metode komunikasi data sekaligus, yaitu GSM/GPRS dan satelit. Alat dapat diatur agar berusaha mencari/mendapatkan sinyal GSM/GPRS terlebih dahulu, jika tidak dapat baru menggunakan komunikasi satelit.

\section{Pada penggunaan jaringan GSM/GPRS} tampaknya tidak banyak mengalami kesulitan sebab saat ini di Indonesia ada beberapa perusahaan/operator telekomunikasi seluler. Kementerian Kelautan dan Perikanan dapat bekerja sama dengan perusahaan di bidang telekomunikasi untuk menerbitkan kartu SIM (SIM card) khusus untuk e-log book. Kartu khusus ini memiliki masa aktif dan atau masa tenggang yang lebih lama dibanding kartu SIM biasa. Hal ini karena waktu operasional kapal penangkap ikan, terutama yang beroperasi di laut lepas bisa mencapai beberapa bulan. Selain itu, kartu khusus tersebut bisa diatur untuk hanya dapat mengirim/menerima data teks saja, tidak untuk suara (voice). Dengan demikian, biaya pulsa dapat menjadi lebih murah.

Pada penggunaan teknologi komunikasi satelit dapat didukung oleh beberapa sistem satelit komunikasi yang beroperasi di Indonesia dan sudah digunakan untuk implementasi VMS pada Kementerian Kelautan dan Perikanan. Untuk menghemat biaya air time satelit, maka e-log book dapat diintegrasikan dengan transmitter VMS yang sudah dipasang di kapal perikanan berukuran di atas $30 \mathrm{GT}$.
Dengan memperhatikan kelebihan dan kekurangan dua metode komunikasi data tersebut, maka penggunaan teknologi GSM/GPRS lebih tepat diterapkan untuk kapal-kapal kecil. Sedangkan penggunaan teknologi satelit dapat diterapkan untuk kapal-kapal besar, terutama yang sudah menggunakan transmitter VMS.

\section{d. Penerima Data}

Bagian penerima data berfungsi sebagai pusat data/sistem integrator yang mengendalikan keseluruhan sistem e-log book. Sistem integrator ini harus dapat menyimpan dan menganalisis data dari semua kapal yang menggunakan e-log book. Berdasarkan Peraturan Menteri kelautan dan Perikanan No. 48/PERMEN-KP/2014, penerapan log book diberlakukan untuk kapal-kapal penangkap ikan berukuran di atas 5 GT. Saat ini, jumlah kapal perikanan berukuran di atas 5 GT adalah sekitar 62.120 kapal (Kementerian Kelautan dan Perikanan, 2014). Jika kenaikan rata-rata jumlah kapal dalam lima tahun berkisar $10 \%$, maka sistem integrator yang dibangun harus dapat menyimpan dan menganalisis data untuk 70.000 kapal dalam waktu 5 tahun.

Data $e$-log book ini merupakan data yang bersifat rahasia. Oleh karena itu, sistem integrator juga harus dapat menjamin keamanan data yang dapat diatur menurut tingkat kompetensi/kewenangan pengguna data (Tarigan \& Ferindra, 2003).

Perangkat pada sistem integrator ini secara umum dapat dibedakan atas konfigurasi sistem tertutup (closed system) dan konfigurasi sistem terbuka (open system). Pada konfigurasi sistem tertutup, perangkat sistem integrator hanya dimungkinkan menerima data dan informasi dari satu sistem jaringan komunikasi tertentu saja. Sebaliknya pada konfigurasi sistem terbuka, perangkat sistem integrator dapat berfungsi untuk mengintegrasikan data dan informasi dari berbagai sistem jaringan komunikasi yang berbeda. Untuk kebutuhan pemeliharaan dan pengembangan sistem integrator ini, diperlukan perusahaan yang memiliki latar belakang teknologi informasi (Tarigan \& Ferindra, 2003). 
Saat ini, Ditjen Perikanan Tangkap sudah membangun SILOPI yang menerima dan menyimpan data log book dari pelabuhan perikanan. Untuk pembangunan sistem integrator ini, dapat menggunakan SILOPI yang sudah dibangun, dengan mengintegrasikan e-log book dengan SILOPI.

\section{Penerapan E-Log Book di Negara Lain}

Untuk memperoleh gambaran terhadap penerapan e-log book penangkapan ikan di negara lain, dilakukan studi literatur terhadap penerapan elektronik log book penangkapan ikan di sejumlah negara (Tabel 2). Hasil studi literatur ini dapat dijadikan sebagai acuan dan selanjutnya dibandingkan dengan ketersediaan sumber daya di Indonesia untuk penerapan $e$-log book.

Tabel 2. Penerapan e-log book di beberapa negara

Table 2. Application of e-log book in several countries

Negara

Filipina - Dimulai sejak November 2013, E-log book berbasis android.

- Pengiriman data menggunakan satelit.

- Fitur lainnya: email dan informasi cuaca.

- Data $e$-log book dikirim oleh observer di kapal perikanan secara real time.

- Tingkat kesuksesan di atas $80 \%$ (berdasarkan perbandingan jumlah kapal yang melaporkan dengan jumlah kapal yang beroperasi).

(Sumber: CLS Argos Indonesia, 2014)

Australia • Dimulai sejak awal 2000

- Saat ini hanya ada dua perusahaan yang memasok perangkat lunak $e$-log book yang digunakan oleh Australian Fisheries Management Authoritiy (AFMA), yaitu CatchLog dan OLRAC.

(Sumber: AFMA, 2014)

Irlandia - Ada 3 tahap implementasi e-log book:

- Kapal perikanan berukuran panjang di atas 24 m mulai 1 Januari 2010.

- Kapal perikanan berukuran panjang di atas 15 m mulai 1 Juli 2011.

- Kapal perikanan berukuran panjang di atas 12 m mulai 1 Januari 2012.

- Komunikasi data menggunakan satelit (Inmarsat Satlink FB 250).

(Sumber: Allen, P., 2009)

Islandia • Sejak 1999, kapal-kapal perikanan di Islandia mulai menggunakan e-log book untuk menggantikan log book kertas.

- Sejak 1 Februari 2008, e-log book diwajibkan untuk digunakan di kapal perikanan ukuran di atas 45 GT. Kemudian mulai 1 Oktober 2008, seluruh kapal perikanan diwajibkan untuk menggunakan $e$-log book.

(Sumber: European Commission, 2008)

Denmark • Uji coba (pilot project) pada Maret 2004.

- Mulai diproduksi pada September 2007.

- Komunikasi data menggunakan satelit (Inmarsat C).

(Sumber: Ministry of Food, Agriculture and Fisheries of Denmark, 2008)

Spanyol - Tingkat kepatuhan kapal perikanan terhadap kuota penangkapan diawasi melalui Electronic Reporting System (ERS).

- ERS merupakan sistem pelaporan hasil tangkapan elektronik ( $e$-log book) yang wajib dimiliki kapal perikanan berukuran di atas 15 meter. Kapal perikanan berukuran 10-15 meter diwajibkan melaporkan hasil tangkapannya melalui log book yang diisi secara manual. Kapal berukuran di bawah 10 meter hanya wajib melaporkan nota penjualan (sales note).

- Kewajiban penggunaan ERS berlaku sejak tahun 2009. 


\begin{tabular}{|c|c|}
\hline & $\begin{array}{l}\text { - Kapal perikanan yang memiliki ERS diwajibkan untuk melaporkan hasil tangkapan dalam } \\
\text { waktu 1x24 jam, walaupun tidak ada hasil tangkapan sama sekali. } \\
\text { - Terdapat sekitar 2.000 kapal berbendera Spanyol yang diwajibkan memiliki ERS. } \\
\text { - Sebelum kapal perikanan berlayar, petugas pengawas pelabuhan melakukan pemeriksaan atas } \\
\text { aktivasi transmitter ERS di kapal. Pada saat kapal berlayar, pengawasan dilakukan melalui Pusat } \\
\text { Pengawasan Pergerakan Kapal Perikanan } \\
\text { - Pemerintah Spanyol juga melakukan inspeksi di atas kapal di tengah laut (at sea on-board } \\
\text { inspection). } \\
\text { (Sumber: Asydhad, A., 2016) }\end{array}$ \\
\hline $\begin{array}{c}\text { Amerika } \\
\text { Serikat }\end{array}$ & $\begin{array}{l}\text { - } \text { Dikembangkan sejak } 2007 . \\
\text { - } \quad \text { Nama program: Cellular Electronic Logbooks (cELB). } \\
\text { - data penangkapan udang di Teluk Meksiko } \\
\text { - } \text { Klat dengan fitur yang dapat mencatat posisi kapal secara otomatis setiap } 10 \text { menit. } \\
\text { - Pada awal 2014, } 500 \text { kapal penangkap udang dipilih untuk membawa cELB di kapal mereka. } \\
\text { (Sumber: NOAA Fisheries, 2014) }\end{array}$ \\
\hline Kanada & $\begin{array}{l}\text { - Pembangunan prototipe pada } 2005 . \\
\text { - Nama perangkat lunak: DFO E-Log. } \\
\text { - } \text { DFO E-Log merupakan aplikasi berbasis Windows. } \\
\text { - } \text { Beberapa pilihan untuk transmisi data (satelit, telepon selular, LAN). } \\
\text { - Pada 2012, } 180 \text { kapal perikanan menggunakan DFO E-Log dalam Proyek Lobster Quebec. } 120 \\
\text { kapal menggunakan laptop berbasis Windows dan } 60 \text { kapal menggunakan iPad. } \\
\text { (Sumber: Goruk, R. \& C. McConnel, 2013) }\end{array}$ \\
\hline
\end{tabular}

Dengan melihat perbandingan penerapan e-log book penangkapan ikan di negara lain, serta melihat kondisi di Indonesia, maka ada beberapa hal yang dapat dijadikan acuan untuk penerapan penerapan $e-\log$ book di Indonesia. Perangkat keras dapat menggunakan produk yang sudah tersedia di pasaran. Filipina telah menggunakan $e$ log book berbasis android. Saat ini di Indonesia telepon pintar dengan sistem operasi android banyak tersedia di pasaran. Sistem transmisi data pada $e$-log book dapat melihat pada penerapan di Kanada, yaitu menggunakan beberapa pilihan transmisi data (satelit / jaringan seluler) yang dapat disesuaikan dengan kebutuhan. Sebagaimana penerapan di Irlandia dan Islandia, maka penerapan e-log book di Indonesia dapat dilakukan secara bertahap. Tahap awal diterapkan terlebih dahulu untuk kapal-kapal berukuran di atas 30 GT yang sudah menggunakan VMS. Tahap berikutnya dapat ditrerapkan untuk kapalkapal perikanan ukuran di bawah 30 GT. Langkah Spanyol dalam penggunaan e-log book yang kemudian ditindaklanjuti inspeksi secara berkala perlu dicontoh dalam penerapan e-log book di Indonesia.

\section{Analisis Kesenjangan Penerapan Teknologi E-Log Book di Indonesia}

Dengan melihat aspek teknis pada teknologi $e$-log book, studi literatur tentang penerapan e-log book di sejumlah negara, serta melihat kondisi saat ini di Indonesia, maka dapat dibuat analisis kesenjangan penerapan teknologi e-log book di Indonesia (Tabel 3). 
Tabel 3. Analisis kesenjangan penerapan teknologi $e$-log book di Indonesia

Table 3. Application gap analysis of e-log book technology in Indonesia

\begin{tabular}{|c|c|c|c|}
\hline $\begin{array}{l}\text { Aspek } \\
\text { Teknologi/ } \\
\text { Peraturan }\end{array}$ & Kondisi Ideal & Kondisi Saat ini di Indonesia & Catatan \\
\hline Perangkat Keras & $\begin{array}{l}\text { Tersedia perangkat keras } \\
\text { yang dapat digunakan } \\
\text { sebagai } e \text {-log book. }\end{array}$ & $\begin{array}{l}\text { Saat ini di pasaran ada beberapa } \\
\text { perangkat yang dapat digunakan } \\
\text { sebagai perangkat keras } e \text {-log } \\
\text { book, yaitu telepon pintar dan } \\
\text { komputer tablet. }\end{array}$ & $\begin{array}{l}\text { Perlu dibuat } \\
\text { standardisasi / sertifikasi } \\
\text { untuk perangkat keras } e- \\
\log \text { book. }\end{array}$ \\
\hline Perangkat lunak & $\begin{array}{l}\text { - Tersedia fitur/ aplikasi } \\
\text { e- log book dengan } \\
\text { format sesuai dengan } \\
\text { peraturan yang } \\
\text { berlaku. } \\
\text { - Tersedia fitur/ aplikasi } \\
\text { yang dapat menunjang } \\
\text { aktivitas penangkapan } \\
\text { ikan. }\end{array}$ & $\begin{array}{l}\text { - Telah dikembangkan aplikasi } \\
\text { fitur/ aplikasi } \text { e-log book sesuai } \\
\text { dengan Peraturan Menteri KP } \\
\text { No. 48/PERMEN-KP/2014. } \\
\text { - Telah dikembangkan fitur pada } \\
\text { e-log book yang memuat } \\
\text { informasi prakiraan daerah } \\
\text { penangkapan ikan, informasi } \\
\text { cuaca, informasi harga ikan. }\end{array}$ & $\begin{array}{l}\text { Perlu dibuat } \\
\text { standardisasi format isian } \\
\text { dan format data } e-\log \\
\text { book. }\end{array}$ \\
\hline $\begin{array}{l}\text { Komunikasi data } \\
\text { (satelit) }\end{array}$ & $\begin{array}{l}\text { Tersedia satelit } \\
\text { komunikasi yang secara } \\
\text { terus-menerus dapat } \\
\text { mengawasi area perairan } \\
\text { dan ZEE Indonesia. }\end{array}$ & $\begin{array}{l}\text { Tersedia beberapa jenis satelit } \\
\text { komunikasi di Indonesia. }\end{array}$ & $\begin{array}{l}\text { Sistem e-log book yang } \\
\text { akan dibangun dapat } \\
\text { menggunakan berbagai } \\
\text { jenis satelit komunikasi. }\end{array}$ \\
\hline $\begin{array}{l}\text { Komunikasi data } \\
\text { (GSM/GPRS) }\end{array}$ & $\begin{array}{l}\text { Tersedia jaringan seluler } \\
\text { yang dapat menjangkau } \\
\text { seluruh Indonesia. }\end{array}$ & $\begin{array}{l}\text { Tersedia beberapa perusahaan } \\
\text { operator seluler di Indonesia. }\end{array}$ & $\begin{array}{l}\text { Dapat bekerja sama } \\
\text { dengan operator seluler } \\
\text { untuk penerbitan kartu } \\
\text { SIM dan pulsa khusus } \\
\text { untuk } e \text {-log book. }\end{array}$ \\
\hline Sistem integrator & $\begin{array}{l}\text { - Terdapat sistem } \\
\text { integrator yang } \\
\text { berfungsi sebagai } \\
\text { pusat data yang } \\
\text { mengendalikan } \\
\text { keseluruhan sistem } \\
\text { elektronik log book. } \\
\text { - Mampu menerima data } \\
\text { dari berbagai operator / } \\
\text { provider. } \\
\text { - Dapat menjamin } \\
\text { keamanan dan } \\
\text { kerahasiaan data } \\
\text { elektronik log book. }\end{array}$ & $\begin{array}{l}\text { - Ditjen Perikanan Tangkap } \\
\text { sudah membangun SILOPI. } \\
\text { - Hanya menerima data dari } \\
\text { pelabuhan (input data log book } \\
\text { ke dalam SILOPI oleh petugas } \\
\text { pelabuhan) } \\
\text { - Data SILOPI hanya bisa } \\
\text { diakses oleh pihak yang } \\
\text { berwenang. }\end{array}$ & $\begin{array}{l}\text { Data dari elektronik log } \\
\text { book bisa diintegrasikan } \\
\text { dengan SILOPI }\end{array}$ \\
\hline $\begin{array}{l}\text { Landasan } \\
\text { peraturan }\end{array}$ & $\begin{array}{l}\text { Perlu adanya landasan } \\
\text { peraturan sebagai dasar } \\
\text { penerapan } e \text {-log book. }\end{array}$ & $\begin{array}{l}\text { Peraturan Menteri KP No. } \\
\text { 48/PERMEN-KP/2014 belum } \\
\text { mengatur tentang elektronik log } \\
\text { book. }\end{array}$ & $\begin{array}{l}\text { Perlu dibuat rekomendasi } \\
\text { dari Balitbang KP } \\
\text { tentang penerapan } \\
\text { teknologi } e \text {-log book. }\end{array}$ \\
\hline
\end{tabular}


Dari hasil analisis kesenjangan pada Tabel 3, dapat disimpulkan bahwa e-log book dapat diterapkan di Indonesia, dengan beberapa catatan. Secara teknologi (perangkat keras, peramgkat lunak, komunikasi data, dan sistem integrator) $e$ log book siap digunakan di Indonesia. Sedangkan dari sisi landasan peraturan, perlu dibuat suatu peraturan hukum sebagai landasan bagi penerapan $e$-log book di Indonesia.

\section{Strategi Penerapan E-Log Book}

Agar teknologi e-log book penangkapan ikan dapat diterapkan, dapat dilakukan strategi sebagai berikut:

1. Penerapan di pelabuhan perikanan dengan tingkat kepatuhan pelaksanaan log book yang tinggi. Untuk tahap awal penerapan e-log book, dapat dilakukan di pelabuhan perikanan dengan tingkat kepatuhan pelaksanaan log book penangkapan ikan yang tinggi. Tingkat kepatuhan pelaksanaan log book yang tinggi tersebut didasarkan pada beberapa kriteria, yaitu: ketepatan waktu penyampaian (entry) data log book penangkapan ikan, kesesuaian ikan hasil tangkapan dengan alat penangkap ikan, kesesuaian ikan hasil tangkapan dengan daerah penangkapan ikan, kesesuaian lama trip dengan jumlah setting, posisi penangkapan, kelengkapan data $\log$ book penangkapan ikan yang disampaikan dientry petugas log book di pelabuhan, dan pembinaan pelabuhan perikanan terhadap pelaku usaha perikanan terkait pelaksanaan log book penangkapan ikan (PPN Pemangkat, 2013). Berdasarkan kriteria tersebut, maka terdapat pelabuhan dengan tingkat kepatuhan pelaksanaan log book yang tinggi pada 2012, yaitu: PPS Nizam Zachman, PPN Ternate, PPN Pemangkat, dan PPP Kwandang (PPS Nizam Zachman, 2013).

2. Penerapan di kapal-kapal penangkap ikan yang sudah menggunakan transmitter VMS. Tahap awal penerapan e-log book juga dapat dilakukan terhadap kapal-kapal yang sudah menggunakan transmitter VMS (Vessel Monitoring System). Operasionalisasi dan penyelenggaraan VMS untuk kapal perikanan saat ini diatur dengan Peraturan Menteri Kelautan dan Perikanan Nomor 10/PERMENKP/2013 tentang Sistem Pemantauan Kapal Perikanan. Peraturan ini mewajibkan kapal perikanan berukuran di atas 30 GT yang beroperasi di perairan Indonesia atau di laut lepas wajib memasang transmitter VMS online dengan pengiriman data posisi kapal tiap 1 (satu) jam secara terus-menerus.

3. Sosialisasi dan pelatihan penggunaan elektronik log book kepada nelayan secara intensif. Saat elektronik log book diterapkan, perlu dilakukan sosialisasi dan pelatihan langsung kepada nakhoda secara intensif dengan bahasa yang sederhana/ mudah dipahami. Sosialisasi dan pelatihan ini juga diberikan kepada petugas pelabuhan, sehingga mereka dapat memberikan pelatihan secara langsung kepada nelayan / nakhoda. Sosialisasi ini juga dapat dilakukan dengan melibatkan tokoh masyarakat setempat.

4. Pemberian sanksi yang tegas terhadap pelanggaran pelaksanaan elektronik log book. Log book penangkapan ikan merupakan dokumen yang dipersyaratkan untuk memperoleh Sertifikat Hasil Tangkapan Ikan (SHTI) yang merupakan dokumen penting untuk melakukan ekspor tuna, serta untuk penerbitan surat tanda bukti lapor kedatangan kapal perikanan oleh syahbandar perikanan (Direktorat Jenderal Perikanan Tangkap, 2013). Sementara itu pada Peraturan Menteri Kelautan dan Perikanan No. 48/PERMEN$\mathrm{KP} / 2014$, log book penangkapan ikan merupakan dokumen yang diperlukan untuk penerbitan Surat Persetujuan Berlayar (SPB). Dalam peraturan tersebut, diatur sanksi bagi kapal yang tidak melaporkan log book. Sanksi tersebut berupa tidak diterbitkannya Surat Persetujuan Berlayar (SPB), pembekuan Surat Izin Panangkapan Ikan (SIPI), sampai pencabutan SIPI. Agar penerapan elektronik log book dapat berjalan dengan baik, maka perlu dilakukan pemberian sanksi yang tegas dan konsisten terhadap pelanggaran pelaksanaannya. Selain sanksi, perlu juga diberikan penghargaan terhadap kapal dengan

JURNAL KELAUTAN NASIONAL, Vol. 10, No. 3, Desember 2015, Hal. 113-124 
kepatuhan pelaksanaan elektronik log book yang tinggi. Penghargaan tersebut dapat berupa kemudahan dalam proses perizinan, kemudahan dalam memperoleh subsidi bahan bakar, serta kemudahan dalam memperoleh bantuan dari pemerintah.

5. Melakukan kerja sama dengan pihak ketiga. Untuk meringankan beban nelayan dalam biaya pengadaan perangkat keras dan biaya pulsa $e$-log book, Kementerian Kelautan dan Perikanan dapat melakukan kerja sama dengan pihak ketiga atau swasta dalam bidang komunikasi untuk penyediaan perangkat keras, penerbitan kartu SIM dan pulsa khusus untuk e-log book.

\section{KESIMPULAN DAN SARAN}

\section{Kesimpulan}

Keakuratan data penangkapan ikan sangat diperlukan untuk mendukung pengelolaan sumber daya ikan. Untuk itu, salah satu cara untuk memperoleh data penangkapan ikan adalah dengan penggunaan log book penangkapan ikan. Penggunaan teknologi e-log book merupakan pilihan yang tepat saat ini guna mempercepat dan meningkatkan akurasi data penangkapan ikan.

Tahapan pengembangan teknologi $e$-log book oleh Badan Penelitian dan Pengembangan Kelautan dan Perikanan berlangsung selama periode 20112014. Pada 2014, dikembangkan teknologi e-log book berbasis android. Format data pada aplikasi android menyesuaikan dengan format data $\log$ book pada Peraturan Menteri Kelautan dan Perikanan No. 48/PERMEN-KP/2014.

Penerapan e-log book di Indonesia dapat dilakukan dengan melihat perbandingan penerapan $e$-log book penangkapan ikan di negara lain, serta melihat kondisi di Indonesia.

Berdasarkan analisis kesenjangan penerapan teknologi e-log book di Indonesia, maka secara teknologi, e-log book yang dikembangkan sudah siap untuk digunakan dalam bidang pengelolaan sumber daya ikan ditinjau dari aspek perangkat keras, perangkat lunak, komunikasi data (satelit dan GSM/GPRS), dan sistem integrator.
Sedangkan dari sisi landasan peraturan, perlu dibuat suatu peraturan hukum sebagai landasan bagi penerapan $e-\log$ book di Indonesia.

\section{Saran}

Dalam penggunaan $e$-log book diperlukan strategi penerapannya yang direkomendasikan seperti: (i) penerapan e-log book dapat di pelabuhan perikanan dengan tingkat kepatuhan pelaksanaan log book yang tinggi dan di kapal-kapal penangkap ikan yang sudah menggunakan transmitter VMS; (ii) sosialisasi dan pelatihan penggunaan elektronik log book kepada nelayan secara intensif; (iii) pemberian sanksi yang tegas terhadap pelanggaran pelaksanaan elektronik $\log$ book; dan (iv) melibatkan pihak ketiga seperti perusahan swasta di bidang teknologi komunikasi.

\section{DAFTAR PUSTAKA}

Allen, P. (2009). Electronic Recording and Reporting System (ERS). Paper presented at ERS Best Practices Workshop. Riga, Latvia. November.

AFMA. (2014). Electronic logbooks. http://www.afma.gov.au/services-forindustry/logbooks-and-catch-disposal/elogbooks.

Asydhad, A. (2016). Cara Spanyol Awasi Kapal Ikan dan Hasil Tangkapan Ikan. https://news.detik.com/berita/3219382/caraspanyol-awasi-kapal-ikan-dan-hasiltangkapan-ikan

CLS Argos Indonesia. (2014). CLS Android-based solutions for Electronic Reporting Systems (ERS). Jakarta.

Direktorat Jenderal Perikanan Tangkap. (2014). Laporan Akuntabilitas Instansi Pemerintah Tahun 2013 - Direktorat Jenderal Perikanan Tangkap. Kementerian Kelautan dan Perikanan. 105 hal.

Direktorat Sumber Daya Ikan. (2014). Peluang Pemanfaatan E-Logbook Penangkapan Ikan untuk Mendukung Pengelolaan Sumberdaya Ikan yang Berkelanjutan. Makalah disampaikan pada Pertemuan dan Diskusi tentang Elektronik Log Book Penangkkapan Ikan. Jakarta. November.

European Commission. (2008). Status of electronic log-books and surveillance in the Icelandic fisheries.

http://ec.europa.eu/fisheries/cfp/control/technol 
ogies/

meetings/290408_logbook_iceland_en.pdf.

Goruk, R. \& C. McConnel. (2013). Fisheries and Oceans Canada's Electronic Networks - Agents of Change to Improve Commercial and Recreational Fishery Management Information. Paper presented at $7^{\text {th }}$ International Fisheries Observer and Monitoring Conference. Vina del Mar, Chile. April.

Kementerian Kelautan dan Perikanan dan Japan International Cooperation Agency (KKP dan JICA). (2009). Textbook Pengelolaan Sumber Daya Perikanan. Kementerian Kelautan dan Perikanan. 56 hal.

Marzuki, M. I. (2011). Membangun Elektronik Logbook Perikanan untuk Menunjang Pengelolaan Sumber Daya Ikan yang Berkelanjutan. Bunga Rampai: Application of Sustainable Development Technology in Indonesia. Jakarta: Pusat Pengkajian dan Perekayasaan Teknologi Kelautan dan Perikanan. Hal. 53-59.

Marzuki, M. I. \& H. Nugroho. (2013). Rancang Bangun Elektronik Log Book Perikanan Berbasis GPRS untuk Mendukung Pengelolaan Perikanan Berkelanjutan. Prosiding Seminar Hasil Penelitian Terbaik Tahun 2013. Jakarta: Badan Penelitian dan Pengembangan Kelautan dan Perikanan. Hal. 164-179.

Ministry of Food, Agriculture and Fisheries of Denmark. (2008). The Danish Elog Project. Paper presented at ERS Technical Meeting. Madrid, Spain. Februari

NOAA Fisheries. (2014). SPGM Electronic Log Book. http://www.galvestonlab.sefsc.noaa.gov/ELB.

Noviyanti, R. (2011). Kondisi Perikanan Tangkap di Wilayah Pengelolaan Perikanan (WPP) Indonesia. 6 hal. Diunduh dari www.pustaka.ut.ac.id/dev25/pdfprosiding2/ fmipa201130.pdf.

Nugroho, H. \& A. Sufyan. (2014). Pengembangan Perangkat Keras Elektronik Log Book Penangkapan Ikan Berbasis Layar Sentuh. Jurnal Kelautan Nasional 9 (1), 93-109.

PPN Pemangkat. (2013). Piagam Penghargaan. 1 hal. Diunduh dari http://ppnpemangkat.blogspot.com/2013/07/pi agam-penghargaan.html.

PPS Nizam Zachman. (2013). Penghargaan Penerapan Log Book Penangkapan Ikan (LBPI) dengan Konsisten. 1 hal. Diunduh dari http://www.ppsnzj.info/?p=207.

Republik Indonesia. (2010). Peraturan Menteri Kelautan dan Perikanan No. PER.18/MEN/2010 tentang Log Book Penangkapan Ikan. Jakarta.
Republik Indonesia. (2013). Peraturan Menteri Kelautan dan Perikanan Nomor 10/PERMENKP/2013 tentang Sistem Pemantauan Kapal Perikanan. Jakarta.

Republik Indonesia. (2014). Peraturan Menteri Kelautan dan Perikanan No. 48/PERMENKP/2014 tentang Log Book Penangkapan Ikan. Jakarta.

Tarigan, H. \& T. D. Ferindra. (2003). Penentuan Desain Sistem Pemantauan Kapal (VMS) Indonesia. Jurnal Riset IPTEK Kelautan. 1(1): 17-26.

JURNAL KELAUTAN NASIONAL, Vol. 10, No. 3, Desember 2015, Hal. 113-124 